\title{
Cytokine profile: recent advances in pathogenesis of intestinal bowel diseases
}

\author{
Ainur Doszhan ${ }^{1}$, Roza Bektayeva ${ }^{1}$, Aiman Galiyeva ${ }^{1}$, Aliya Kurmankina ${ }^{2}$, \\ Kapura Adrissova $^{1}$, Kazbek Agibayev ${ }^{3}$, Maiya Zhumabayeva ${ }^{4}$
}

${ }^{1}$ Department of Gastroenterology and Infectious Diseases, Astana Medical University, Astana, Republic of Kazakhstan

${ }^{2}$ Clinical diagnostic laboratory, Medical Centre Hospital of President's Affairs Administration of the Republic of Kazakhstan, Astana, Republic of Kazakhstan

${ }^{3}$ Center for Coloproctology and Surgical Infections, Municipal Hospital $\mathrm{No}^{1}$, Astana, Republic of Kazakhstan ${ }^{4}$ Department of Scientific Research Management, National Scientific Medical Center, Astana, Republic of Kazakhstan

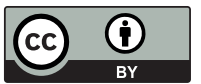

This work is licensed under a Creative Commons Attribution 4.0 International License

Received: 2018-02-27

Accepted: 2018-03-14

UDC: 616.1

J Clin Med Kaz 2018;1(47):14-17

Corresponding Author: Ainur Doszhan, Department of Gastroenterology and Infectious Diseases, Astana Medical University. Astana, Republic of Kazakhstan. Tel.: 87017709708

E-mail: doszhan_88_88@mail.ru

\section{Abstract}

Inflammatory bowel diseases, including ulcerative colitis and Crohn's disease, remain an urgent problem of clinical gastroenterology. Although the etiology of both diseases is still unknown, in recent years progress has been made in studying of pathogenesis of inflammatory processes in patients with inflammatory bowel diseases. In particular, recent data from the foreign literature on the immune dysregulation demonstrate the important roles of novel IL-1 family and the IL-6 family in the inflammatory bowel diseases development, which can determine their diagnostic value and the personalized therapeutic strategy in such patients in the future.

Key words: ulcerative colitis, Crohn's disease, cytokine profile, tumor necrosis factor, interleukins

\section{ЦИТОКИН ПРОФИЛІНІҢ ЕРЕКШЕЛІКТЕРІ: ІШЕК ҚАБЫНУ АУРУЛАРЫНЫҢ ПАТОГЕНЕЗІН ЗЕРТТЕУДЕГІ СОНҒЫ} ЖЕТІСТІКТЕРI

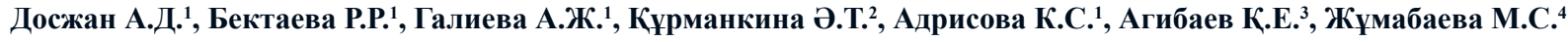

'Гастроэнтерология және жұқпалы аурулар кафедрасы, Астана медициналық университеті, Астана, Қазақстан Республикасы

${ }^{2}$ Клинико-диагностикалық лабараториясы, Қазақстан Республикасы Президенті Іс Басқармасы медициналық орталығы ауруханасы, Астана, Қазақстан Республикасы

${ }^{3}$ Колопроктология және хирургиялық инфекциялар орталығы, №1 қалалық ауруханасы, Астана, Қазақстан Республикасы

"Ғылыми зерттеулер менеджменті бөлімі, Ұлттық ғылыми медициналық орталық, Астана, Қазақстан Республикасы

\section{ТҰЖЫРЫМДАМА}

Клиникалық гастроэнтерологияның өзекті мәселесі - ішек қабыну ауруларын қоса алғанда, ішектің колиті және Крон ауруы. Екі аурудың этиологиясы әлі белгісіз болса да, соңғы жылдары ішек қабыну аурулары бар науқастарда қабыну процестерінің күрделі патогенетикалық механизмдерін зерттеуде елеулі прогресске қол жеткізілді. Атап айтқанда, иммундық реттеулер туралы шетелдік әдебиеттердегі соңғы деректер ИЛ-1 отбасының цитокиндері мен IL-6 отбасының диагностикалық құндылығын анықтауға мүмкіндік беретін, сонымен қатар келешекте IКА бар науқастарда дараланған терапевтік тәсілдің дамуына ықпал ететін ІКА даму механизмдерінде маңызды рөлін көрсетеді.

Негізгі сөздер: ішек қабыну ауруы, Крон ауруы, цитокин профилі, ісік некрозының факторы, интерлейкиндер

\section{ОСОБЕННОСТИ ЦИТОКИНОВОГО ПРОФИЛЯ: ПОСЛЕДНИЕ ДОСТИЖЕНИЯ В ИЗУЧЕНИИ ПАТОГЕНЕЗА} ВОСПАЛИТЕЛЬНЫХ ЗАБОЛЕВАНИЙ КИШЕЧНИКА

Досжан А.Д. ${ }^{1}$, Бектаева P.Р. ${ }^{1}$, Галиева А.Ж. ${ }^{1}$, Курманкина А.Т. ${ }^{2}$, Адрисова К.С. ${ }^{1}$, Агибаев К.Е. ${ }^{3}$, Жумабаева М.С. ${ }^{4}$

${ }^{1}$ Кафедра гастроэнтерологии и инфекционных болезней, Медицинский университет Астана, Астана, Республика Казахстан

${ }^{2}$ Клинико-диагностическая лаборатория, Больница медицинского центра управления делами Президента Республики Казахстан, Астана, Республика Казахстан

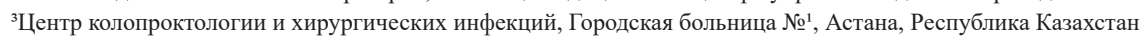

${ }^{4}$ Отдел менеджмента научных исследований, Национальный научный медицинский центр, Астана, Республика Казахстан

\section{PEЗЮME}

Воспалительные заболевания кишечника, к которым относятся язвенный колит и болезнь Крона, остаются актуальной проблемой клинической гастроэнтерологии. Хотя этиология обоих заболеваний до сих пор неизвестна, в последние годы был достигнут значительный прогресс в изучении сложных патогенетических механизмов воспалительных процессов у пациентов с этой патологией. В частности, последние данные зарубежной литературы об иммунной дисрегуляции свидетельствуют о важной роли новых цитокинов семейства IL-1 и семейства IL-6 в механизмах развития воспалительных заболеваний кишечника, что может определить их диагностическую ценность, а также в будущем содействовать разработке персонифицированного терапевтического подхода у данных пациентов.

Ключевые слова: язвенный колит, болезнь Крона, цитокиновый профиль, фактор некроза опухоли, интерлейкины 


\section{Введение}

Воспалительные заболевания кишечника (ВЗК), к которым относятся язвенный колит (ЯК) и болезнь Крона (БК), остаются актуальной проблемой клинической гастроэнтерологии. Показатели заболеваемости и распространенности ВЗК заметно возросли во второй половине двадцатого века, а с начала ХХІ века ВЗК считаются одними из наиболее часто встречающихся патологий желудочно-кишечных тракта [1]. Распространенность ВЗК по данным различных авторов варьирует в широких пределах. В среднем ежегодно диагностируют от 7 до 15 новых случаев на 100000 населения в год [2]. По данным Е. Szigethy et al. в Северной Америке эти показатели колеблются между 3,1 и 14,6 на 100000 человек для болезни Крона и от 2,2 до 14,3 100000 для ЯК соответственно [3]. Актуальность ВЗК подчеркивает тот факт, что данная патология манифестирует в возрасте 20-30 лет, характеризуется прогрессирующим рецидивирующим течением, развитием тяжелых осложнений, непредсказуемостью результатов лечения, тем самым ухудшая прогноз заболевания и качество жизни людей молодого трудоспособного возраста [2, 4].

Хотя этиология обоих заболеваний до сих пор неизвестна, в последние годы был достигнут значительный прогресс в изучении сложных патогенетических механизмов воспалительных процессов у пациентов с ВЗК. Исследования показали, что патогенез ВЗК связан с генетической предрасположенностью, кишечной микробиотой, факторами окружающей среды и иммунологическими нарушениями $[1,2,5,6]$. Иммунологическая дисрегуляция при ВЗК характеризуется эпителиальным повреждением, усилением воспаления, вызванное кишечной флорой и возрастающим количеством клеток, проникающих в собственную пластинку слизистой оболочки, включая Т-клетки, В-клетки, макрофаги, дендритные клетки и нейтрофилы; а также неспособностью иммунной системы контролировать воспалительный ответ $[1,2,7,8]$. Большое количество медиаторов активно секретируется в собственной пластинке слизистой оболочки толстой кишки, включая цитокины с провоспалительной активностью: ФНО- $\alpha$ (фактор некроза опухоли), ИФН- $\gamma$ (инферферон), ИЛ-6 (интерлейкин), ИЛ12, ИЛ-21, ИЛ-23, ИЛ-17 и т. д.; и противовоспалительные цитокины: ИЛ-10, ТФР- $\beta$ (трансформирующий фактор роста), ИЛ-35 и т. д. [6, 7]. БК обычно рассматривают как состояние, при котором наблюдается дисрегуляция популяций Th1-клеток и Th17-клеток с повышенным образованием ИЛ-12, ИЛ-23, ИФН- $\gamma$ и ИЛ-17, тогда как ЯК характеризуется дисбалансом популяций Th2- и Th9клеток и соответственно цитокинов ИЛ-13, ИЛ-5 и ИЛ-9 [7]. Значение цитокинов в инициировании и развитии процессов клеточного и тканевого повреждения была широко изучена, что определило их ключевую роль в патогенезе ВЗК и, следовательно, необходимость рассмотрения их в качестве потенциальной терапевтической мишени $[1,6,8,9]$. Вместе с тем до сих пор остаются открытыми ряд вопросов о цитокиновых профилях при различной активности воспалительного процесса у пациентов с ЯК и БК.

Среди провоспалительных цитокинов одним из наиболее активных является ФНО- $\alpha$ [10]. Суперсемейство белка ФНО состоит из 18 белков типа 2, которые существуют либо в мембраносвязанных, либо в растворимых формах $[11,12]$. Рецепторы для этих лигандов представляют собой трансмембранные белки 1-го типа. Связывание ФНОподобных лигандов с их рецепторами действует как триггер внутриклеточных путей, которые ответственны за процессы пролиферации, дифференцировки и выживания $[11,13$, 14]. Большинство членов суперсемейства ФНО/ФНОрецептора экспрессируются на иммунных клетках и играют критическую роль в иммунном ответе, включая защиту от микроорганизмов, воспаление, клеточный апоптоз и развитие клеток иммунной системы [11-14]. ФНО- $\alpha$ является основным цитокином в патогенезе ВЗК. Он оказывает плейотропное действие посредством экспрессии молекул адгезии, пролиферации фибробластов, прокоагулянтов, инициирует цитотоксические, апоптотические процессы $[12,15]$. Данный мембранный белок обладает способностью увеличиватьпродукциюИЛ-1 $\beta$, ИЛ-6иИЛ-33,имодулировать экспрессию рецепторов ST2 в эпителиальных клетках [12, 16]. ФНО- $\alpha$ при ВЗК синтезируется клетками врожденного иммунитета - макрофагами или моноцитами, а также дифференцированными Тh1-клетками [17]. Неоднократно была доказана прямая корреляция между уровнем ФНОв сыворотке и клинической активностью ЯК и БК [12]. Его роль в воспалении толстой кишки легла в основу разработки биологической терапии для пациентов с ВЗК, а именно ингибиторов ФНО- $\alpha$, блокирующих провоспалительный цитокин ФНО- $\alpha$. ФНО-подобный фактор (TL1A), другой недавно обнаруженный член семейства ФНО, стимулирует секрецию ИФН- $\gamma$ путем связывания с рецептором смерти-3 (DR3). DR3 экспрессируется большим процентом клеток в биоптатах слизистой оболочки больных ЯК и БК, кроме того при активности заболевания у пациентов с ВЗК наблюдается увеличение уровня ИФН- $\gamma$ [18]. Хотя TL1A, по-видимому, участвует в апоптозе интестинальных эпителиальных клеток при ВЗК [17], конкретная роль этого белка в патогенезе ЯК остается до конца неизученной.

Среди огромного числа цитокиновых молекул с различными действиями выделяют отдельные медиаторы, их группы или семейства. Так, ряд цитокинов объединены в семейство ИЛ-1 в зависимости от таких свойств и характеристик, как: функциональная специфичность, гомология аминокислотных последовательностей, третичность белковой структуры, пространственная конфигурация, расположение гена и рецепторное взаимодействие $[19,20]$. Семейство ИЛ-1 включает в себя семь агонистических цитокинов: ИЛ-1 $\alpha$, ИЛ

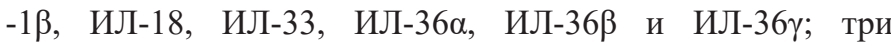
антагониста рецептора: ИЛ-1R $\alpha$, ИЛ-36R $\alpha$, ИЛ-38; и один противовоспалительный цитокин - ИЛ-37. Члены семейства рецепторов ИЛ-1 включают 10 молекул (от ИЛ-1R1 до ИЛ-1R10) [1, 21]. При связывании цитокинов рецепторы ИЛ-1 гетеродимеризуются, что приводит к высвобождению внутриклеточных сигнальных молекул, включая MyD88, IRAK и TRAF6, затем к активации транскрипционных факторов NF-кB, p38, JNK и/или МАРК, это в свою очередь ведет к транскрипции генов-мишеней ИЛ-6, ИЛ5, ИЛ-4, ИЛ-8, МСР-1, и СОХ-2 [22]. Цитокины семейства IL-1 продуцируются клетками врожденного иммунитета. Кроме того, члены семейства IL-1 играют важную роль в дифференциации и функционировании поляризованных клеток врожденного и адаптивного иммунитета. В последних обзорах зарубежных публикаций приведены данные о роли новых цитокинов в патогенезе ВЗК, среди которых особый интерес представляют IL-33, IL-36 и IL-37 [1, 21].

IL-6,IL-11,IL-31,ингибирующий факторлейкемии(LIF), онкостатин M (OSM), кардиотрофин-1 (CT-1), цилиарный нейротрофический фактор (CNTF) и кардиотрофин- 
подобный цитокин (CLC) принадлежат к семейству IL-6. IL-6 представляет собой иммунорегуляторный цитокин. Имеется два вида специфического рецептора ИЛ-6: связанный с мембраной клеток (IL-6R) и растворимый, свободно циркулирующий в крови (sIL-6R), которые активируются при присоединении ИЛ-6. Связывание SIL6R c ИЛ-6 приводит к образованию комплекса, который обладает способностью также связываться со специфической рецепторной субъединицей gр130 и индуцировать передачу ИЛ-6-зависимого активационного сигнала в клетках, неэкспрессирующих IL-6R. Данный механизм называется транс-сигнализацией. Это приводят к активации JAK (Janus family tyrosine kinase) тирозинкиназы (JAK1, JAK2 и Tyk2) $[23,24,25]$, в свою очередь вызывающей рекрутирование и фосфорилирование латентных факторов транскрипции STAT1 (signal transducers and activators of transcription 1) и STAT3, регулирующих синтез широкого спектра «провоспалительных» медиаторов. Передача сигналов IL-6 посредством факторов транскрипции (STAT3) играет важную роль в патогенезе ЯК, и более того, в канцерогенезе колоректального рака, ассоциированного с ЯК $[12,26,27]$. Также было обнаружено, что уровни sIL-6R значительно повышены у пациентов с активным ЯК и БК. Исходя из этих данных, блокирование сигнализации ИЛ-6/STAT3 и использование антител против IL-6R рассматриваются в настоящее время как многообещающие терапевтические стратегии в недалекой перспективе [12].

Таким образом, открытие и изучение новых противовоспалительных цитокинов (например, ИЛ-36 и ИЛ-37) и новых цитокиновых мишеней (например, ИЛ-6/ STAT3) позволят определить их диагностическую ценность в качестве биомаркеров активности воспалительного процесса и разработать персонифицированный терапевтический подход, обеспечивая тем самым прогнозируемое лечение у пациентов с ВЗК.

Disclosures: There is no conflict of interest for all authors.

\section{References}

1. Guan Q, Zhang J. Recent Advances: The Imbalance of Cytokines in the Pathogenesis of Inflammatory Bowel Disease. Mediators of Inflammation. 2017; 2017:4810258.

2. Gastroenterologiya. Natsional'noe rukovodstvo: kratkoe izdanie (National guideline: short edition) [in Russian]. Moscow: GEOTAR-Media; 2015. p. 480.

3. Szigethy EV, McLafferty LA, Goyal AF. Inflammatory bowel disease. Child and Adolescent Psychiatric Clinics of North America. 2010; 19(2):301-318.

4. Ivashkin VT, Shelygin YA, Abdulganieva D I, Abdulkhakov RA, Alekseeva O P, Achkasov SI et al. Rekomendatsii Rossiiskoi gastroenterologicheskoi assotsiatsii i Assotsiatsii koloproktologov Rossii po diagnostike i lecheniyu vzroslykh bol'nykh yazvennym kolitom (Guidelines of the Russian Gastroenterological Association and the Association of Coloproctologists for diagnosis and treatment of adults with ulcerative colitis) [in Russian]. Rossiiskii zhurnal gastroenterologii, gepatologii, koloproktologii. 2015; 1:48-65.

5. Loddo IN, Romano CC. Inflammatory bowel disease: genetics, epigenetics, and pathogenesis. Frontiers in Immunology. 2015; 6:551.

6. Neurath MF. Cytokines in inflammatory bowel disease. Nature Reviews Immunology. 2014; 14(5):329-342.

7. Souza HS, Fiocchi CV. Immunopathogenesis of IBD: current state of the art. Nature Reviews Gastroenterology \& Hepatology. 2016; 13(1):13-27.

8. Ince MN, Elliott DE. Immunologic and molecular mechanisms in inflammatory bowel disease. The Surgical Clinics of North America. 2007; 87(3):681-696.

9. Chen ML., Sundrud MS. Cytokine networks and T-cell subsets in inflammatory bowel diseases. Inflammatory Bowel Diseases. 2016; 22(5):1157-1167.

10. Sagynbaeva VE, Lazebnik LB, Knyazev OV, Efremov LI. Dinamika provospalitel'nykh tsitokinov na fone biologicheskoi terapii vospalitel'nykh zabolevanii kishechnika (Dynamics of proinflammatory cytokines after the biological therapy of inflammatory bowel diseases) [in Russian]. Eksperimental'naya i klinicheskaya gastroenterologiya. 2012; 3:47 - 58.

11. Locksley RM, Killeen NN, Lenardo MJ. The TNF and TNF receptor superfamilies: integrating mammalian biology. Cell. 2001; 104:487-501.

12. Müzes GM, Molnár BN, Tulassay ZF. Changes of the cytokine profile in inflammatory bowel diseases. World Journal of Gastroenteroly. 2012; 18(41):5848-5861.

13. Idriss HT, Naismith JH. TNF alpha and the TNF receptor superfamily: structure-function relationship(s). Microsc ResTech. 2000; 50:184-195.

14. Smith CA, Farrah TM, Goodwin RG. The TNF receptor superfamily of cellular and viral proteins: activation, costimulation, and death. Cell. 1994; 76:959-962.

15. Murch SR, Braegger CD, Walker-Smith JA, MacDonald T. Location of tumour necrosis factor alpha by immunohistochemistry in chronic inflammatory bowel disease. Gut. 1993; 34:1705-1709.

16. Pastorelli LW, Garg RR, Hoang S, Spina LN, Mattioli B, Scarpa M et al. Epithelial-derived IL-33 and its receptor ST2 are dysregulated in ulcerative colitis and in experimental Th1/Th2 driven enteritis. Proc Natl Acad Sci USA. 2010; 107:8017-8022.

17. Begue BN, Wajant HN, Bambou JC, Dubuquoy LN, Siegmund DH, Beaulieu JF et al. Implication of TNF-related apoptosisinducing ligand in inflammatory intestinal epithelial lesions. Gastroenterology. 2006; 130:1962-1974.

18. Bamias GB, Martin CC, Marini M, Hoang S, Mishina MN, Ross W et al. Expression, localization, and functional activity of TL1A, a novel Th1-polarizing cytokine in inflammatory bowel disease. J Immunol. 2003; 171:4868-4874. 
19. Matveeva LV, Mosina LM. Rol' tsitokinov semeistva interleikina-1 v zheludochnom kantserogeneze (The role of cytokines of the interleukin-1 family in gastric carcinogenesis) [in Russian]. Vestnik RAMN.2012; 11.

20. Sims JE, Nicklin MJ, Bazan JF, Barton JL, Busfield SJ, Ford JE et al. A new nomenclature for IL-1-family genes. Trends Immunol. $2001 ; 22: 536-537$.

21. Garlanda CB, Dinarello CA, Mantovani AA. The interleukin-1 family: back to the future. Immunity. 2013; 39(6):1003-1018.

22. Palomo JN, Dietrich DG, Martin P, Palmer GB, Gabay C. The interleukin (IL)-1 cytokine family-balance between agonists and antagonists in inflammatory diseases. Cytokine. 2015; 76(1):25-37.

23. Boulanger MJ, Bankovich AJ, Kortemme T, Baker D, Garcia KC. Convergent mechanisms for recognition of divergent cytokines by the shared signaling receptor gp130. Mol Cell. 2003; 12:577-589.

24. Nasonov EL, Mazurov V I, Usacheva YV. Razrabotki otechestvennykh original'nykh genno-inzhenernykh biologicheskikh preparatov dlya lecheniya immunovospalitel'nykh revmaticheskikh zabolevanii (Developments of Russian original biological agents for the treatment of immunoinflammatory rheumatic diseases) [in Russian]. Rheumatology Science and Practice. 2017;55(2):201-210.

25. Hoene MB, Weigert C. The role of interleukin-6 in insulin resistance, body fat distribution and energy balance. Obesity reviews. 2008; 9:20-29.

26. Li Y, Haar CD, Chen M, Deuring J, Gerrits MM, Smits RB, et al. Disease-related expression of the IL6/STAT3/SOCS3 signalling pathway in ulcerative colitis and ulcerative colitis-related carcinogenesis. Gut. 2010; 59:227-235.

27. Mudter J, Neurath MF. Il-6 signaling in inflammatory bowel disease: pathophysiological role and clinical relevance. Inflamm Bowel Dis. 2007; 13:1016-1023.

How to cite this article: Ainur Doszhan, Roza Bektayeva, Aiman Galiyeva, Aliya Kurmankina, Kapura Adrissova, Kazbek Agibayev, Maiya Zhumabayeva. Cytokine profile: recent advances in pathogenesis of intestinal bowel diseases [in Russian]. J Clin Med Kaz. 2018; 1(47):14-17 